\title{
Simultaneous hydrolysis with lipase and fermentation of rapeseed cake for iturin $A$ production by Bacillus amyloliquefaciens CX-20
}

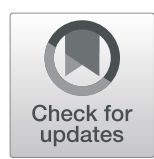

\author{
Wenchao Chen 1,2,4, Xuan $\mathrm{Li}^{1}$, Xuli Ma ${ }^{1}$, Shouwen Chen ${ }^{3}$, Yanping Kang ${ }^{1}$, Minmin Yang ${ }^{1}$, \\ Fenghong Huang ${ }^{1,2,4,5}$ and Xia Wan ${ }^{1,2,4,5^{*}}$
}

\begin{abstract}
Background: Rapeseed cake (RSC), as the intermediate by-product of oil extraction from the seeds of Brassica napus, can be converted into rapeseed meal (RSM) by solvent extraction to remove oil. However, compared with RSM, RSC has been rarely used as a raw material for microbial fermentation, although both RSC and RSM are mainly composed of proteins, carbohydrates and minerals. In this study, we investigated the feasibility of using untreated low-cost RSC as nitrogen source to produce the valuable cyclic lipopeptide antibiotic iturin A using Bacillus amyloliquefaciens CX-20 in submerged fermentation. Especially, the effect of oil in RSC on iturin A production and the possibility of using lipases to improve the iturin A production were analyzed in batch fermentation.

Results: The maximum production of iturin A was $0.82 \mathrm{~g} / \mathrm{L}$ at the optimal initial RSC and glucose concentrations of 90 and $60 \mathrm{~g} / \mathrm{L}$, respectively. When RSC was substituted with RSM as nitrogen source based on equal protein content, the final concentration of iturin A was improved to $0.95 \mathrm{~g} / \mathrm{L}$. The production of iturin A was further increased by the addition of different lipase concentrations from 0.1 to $5 \mathrm{U} / \mathrm{mL}$ into the RSC medium for simultaneous hydrolysis and fermentation. At the optimal lipase concentration of $0.5 \mathrm{U} / \mathrm{mL}$, the maximal production of iturin A reached $1.14 \mathrm{~g} / \mathrm{L}$, which was $38.15 \%$ higher than that without any lipase supplement. Although rapeseed oil and lipase were firstly shown to have negative effects on iturin A production, and the effect would be greater if the concentration of either was increased, their respective negative effects were reduced when used together.

Conclusions: Appropriate relative concentrations of lipase and rapeseed oil were demonstrated to support optimal iturin A production. And simultaneous hydrolysis with lipase and fermentation was an effective way to produce iturin A from RSC using B. amyloliquefaciens CX-20.
\end{abstract}

Keywords: Rapeseed cake, Rapeseed oil, Lipase, Iturin A, Bacillus amyloliquefaciens

\section{Background}

In conventional agricultural cultivation, easy-to-use chemical pesticides and fungicides are commonly used to control plant diseases, which are a major threat to food security worldwide. However, the overuse of these chemicals has raised great concerns due to their side effects such as environmental contamination and harm to human health by the presence of chemical residues in

\footnotetext{
* Correspondence: wanxia@oilcrops.cn

${ }^{1}$ Oil Crops Research Institute of the Chinese Academy of Agricultural Sciences, Wuhan 430062, People's Republic of China

${ }^{2}$ Key Laboratory of Biology and Genetic Improvement of Oil Crops, Ministry of Agriculture, Wuhan 430062, People's Republic of China

Full list of author information is available at the end of the article
}

food [1]. Biological control offers an eco-friendly and sustainable alternative and is become increasingly prevalent in modern agriculture. Among a variety of microorganisms, the genus Bacillus has been widely used as biological control agent due to its production of antimicrobial substances such as the cyclic lipopeptides iturin, fengycin and surfactin [2]. Iturin A, a prominent member of the iturin group, was found to suppress many plant diseases via a combination of its broadspectrum antifungal activity and the activation of plant defense systems [3]. This makes iturin A an ideal potential biological control agent for reducing the use of artificial chemical pesticides in agriculture. In recent years,

(c) The Author(s). 2019 Open Access This article is distributed under the terms of the Creative Commons Attribution 4.0 International License (http://creativecommons.org/licenses/by/4.0/), which permits unrestricted use, distribution, and 
many attempts have been made to use agricultural byproducts, such as rapeseed meal (RSM) $[4,5]$, soybean curd residue [6] and fish meal [7], to realize low-cost and large-scale production of iturin A. For example, Jin et al. $[4,5]$ used untreated RSM as the nitrogen source for the production of iturin A using B. subtilis and enhanced the production two-fold by using a two-stage glucose feeding strategy in liquid fermentation. Yao et al. [8] used B. subtilis to co-produce iturin A and poly- $\gamma$-glutamic acid from RSM in solid-state fermentation.

Rapeseed cake (RSC) and RSM are the major byproducts in the production of rapeseed oil and are mainly composed of proteins, carbohydrates and minerals. Both are good protein resources for animal feed, with a favorable balance of essential and sulfur-containing amino acids [9]. The production process of RSM from RSC involves solvent extraction to remove oil and heating to remove the organic solvent. Although this procedure increases the protein content of RSM compared with RSC, and RSC only contains $30-40 \%$ crude protein in dry matter [10], RSC is considered more suitable for animal diets than solvent-extracted RSM by many scholars. The reasons are as follows: (1) the production technology of RSC is more environmentally friendly [11], (2) RSC has a higher metabolizable energy value due to its higher residual oil content [12], and (3) organic animal production precludes the use of oilseed meal due to the exposure to chemical solvents during the extraction [13]. However, compared with RSM [4, 5, 14-18], there are fewer reports on the use of RSC as a nutrient for microbial fermentations. In addition to obtaining more oil and profits by chemical solvent-extraction, one of the key factors is the high content of oil in RSC, which can influence the titer and productivity of some secondary metabolites [19]. Therefore, if the problem of high oil content in RSC can be solved, it is likely that RSC can be used for microbial production similarly to RSM.

Lipases, which not only hydrolyze triacylglycerides to form glycerol and fatty acids, but can also catalyze the synthesis of esters under certain conditions [20], constitute one of the most important families of industrial enzymes. Following carbohydrases and proteases, lipases are considered the third largest group of enzymes based on total sales volume [21], and are widely applied in the manufacture of foods, fine chemicals, cosmetics, pharmaceuticals, detergents, wastewater treatment, leather processing and biomedical assays [22]. However, unlike carbohydrases and proteases [16], lipases have not been widely used for the pretreatment of rapeseed by-products to improve their value for microbial production. It has been reported that RSC could be used as a valuable raw material for producing lipases and proteases due to its high content of lipids and proteins [23]. Therefore, it seems feasible to use lipases to solve the problem of high oil content in RSC.

RSM has been demonstrated as a more effective nitrogen source than two different commercial nitrogen sources for iturin A production by Bacillus [4]. However, to our best knowledge, there are no reports on the production of iturin A by the fermentation of RSC. In this study, we investigated the feasibility of using untreated low-cost RSC as nitrogen source to produce the valuable cyclic lipopeptide antibiotic iturin A using B. amyloliquefaciens CX-20 in submerged fermentation. Especially, the effect of oil in RSC on iturin A production and the possibility of using lipases to improve the iturin A production were analyzed in batch fermentation.

\section{Methods}

Raw material and enzyme

RSC and RSM used in the experiments were kindly supplied by the Oil Crops Research Institute of the Chinese Academy of Agricultural Sciences (Wuhan, China) and were milled in a commercial plant. The composition of RSC and RSM flour was determined and was shown in Table 1.

The lipase used in this study was kindly supplied by Wuhan Sunhy Biology Co., Ltd. (China). The product is a lipase mixture used as a feed additive with a nominal activity of $10,000 \mathrm{U} / \mathrm{g}$.

\section{Microorganisms and media}

B. amyloliquefaciens CX-20 (CCTCC No. M2018794), a iturin A high- production strain, was kindly provided by professor Shouwen Chen (College of Life Sciences, Hubei University, Wuhan, China). Luria-Bertani (LB) medium (10 g tryptone, $5 \mathrm{~g}$ yeast extract, $10 \mathrm{~g} \mathrm{NaCl}$, and $1 \mathrm{~L} \mathrm{H}_{2} \mathrm{O}$ ) was used for seed cultures of Bacillus. The fermentation medium was composed of $60 \mathrm{~g}$ glucose, $1 \mathrm{~g} \mathrm{~K} \mathrm{~K}_{2} \mathrm{HPO}_{4} \cdot 3 \mathrm{H}_{2} \mathrm{O}, 0.5 \mathrm{~g}$ $\mathrm{MgSO}_{4} \cdot 7 \mathrm{H}_{2} \mathrm{O}, 0.005 \mathrm{~g} \mathrm{MnSO}_{4} \cdot \mathrm{H}_{2} \mathrm{O}, 90 \mathrm{~g}$ RSC or $76.52 \mathrm{~g}$ $\mathrm{RSM}$, and $1 \mathrm{~L} \mathrm{H}_{2} \mathrm{O}$. Flask experiments were performed in $250 \mathrm{~mL}$ flasks with $20 \mathrm{~mL}$ of medium. Due to the insolubility of RSM/RSC, $1.80 \mathrm{~g}$ RSC or $1.53 \mathrm{~g}$ RSM was weighed and placed into each $250 \mathrm{~mL}$ flask in advance, respectively. And then mix with distilled water containing above mentioned concentrations of inorganic salts and glucose to a final volume of $20 \mathrm{~mL}$. The initial $\mathrm{pH}$ of the medium was

Table 1 The components of RSM and RSC

\begin{tabular}{|c|c|c|c|c|c|c|c|}
\hline & Moisture (\%) & Ash (\%) & Crude Protein (\%) & Crude Fat (\%) & Crude fiber (\%) & Neutral detergent fiber (\%) & Acid detergent fiber (\%) \\
\hline RSM & 8.3 & 7.3 & 39.4 & 1.6 & 8.8 & 26.6 & 12.8 \\
\hline RSC & 4.7 & 7.0 & 33.5 & 14.4 & 7.1 & 16.6 & 11.7 \\
\hline
\end{tabular}


adjusted to 7.0 and it was autoclaved at $121{ }^{\circ} \mathrm{C}$ for $30 \mathrm{~min}$. The inoculum size was $5 \%(\mathrm{v} / \mathrm{v})$. All fermentations were carried out at $28^{\circ} \mathrm{C}$ under constant orbital shaking at $220 \mathrm{rpm}$.

\section{Simultaneous hydrolysis and fermentation}

Batch submerged fermentation experiments were performed in $250 \mathrm{~mL}$ flasks with an initial working volume of $20 \mathrm{~mL}$. The medium for submerged fermentation contained (per liter): $60 \mathrm{~g}$ glucose, $1 \mathrm{~g} \mathrm{~K}_{2} \mathrm{HPO}_{4} \cdot 3 \mathrm{H}_{2} \mathrm{O}, 0.5 \mathrm{~g}$ $\mathrm{MgSO}_{4} \cdot 7 \mathrm{H}_{2} \mathrm{O}, 0.005 \mathrm{~g} \mathrm{MnSO}_{4} \cdot \mathrm{H}_{2} \mathrm{O}, 90 \mathrm{~g} \mathrm{RSC}$ or $76.52 \mathrm{~g}$ RSM. Due to the insolubility of RSM/RSC, $1.80 \mathrm{~g}$ RSC was weighed and placed into each $250 \mathrm{~mL}$ flask in advance, respectively. And then mix with distilled water containing above mentioned concentrations of inorganic salts and glucose to a final volume of $20 \mathrm{~mL}$. Submerged fermentation was started by adding $5 \%(\mathrm{v} / \mathrm{v})$ of exponentially growing cells and lipase. Submerged fermentation was conducted at $28^{\circ} \mathrm{C}$ with a rotating speed of 220 $\mathrm{rpm}$. The effects of lipase loading $(0,0.1,0.5,1,5,10 \mathrm{U} /$ $\mathrm{mL})$ and rapeseed oil concentrations $(0,6,12$ and $24 \mathrm{~g} /$ L) on submerged fermentation were investigated.

\section{Extraction and quantitation of iturin $\mathrm{A}$}

Iturin A was extracted according to a reported method $[4,5,24]$. Briefly, $0.3 \mathrm{~mL}$ of the mixed fermentation broth was added into a $2 \mathrm{~mL}$ glass tube containing $1.2 \mathrm{~mL}$ of methanol, shaken well and incubated for $60 \mathrm{~min}$. The mixture was centrifuged at $12,000 \mathrm{rpm}$ for $20 \mathrm{~min}$, and the supernatant was filtered through a $0.22 \mu \mathrm{m}$ pore-size hydrophobic polytetrafluoroethylene (PTFE) type disposable syringe. The iturin A concentration was quantified using a Waters 2695 HPLC system equipped with an ACQUITY UPLC BEA C18 column $(1.7 \mu \mathrm{m} 2.1 \times 100$ $\mathrm{mm}$, Waters, USA). A mixture of acetonitrile and 10 $\mathrm{mM}$ ammonium acetate $(35: 65, \mathrm{v} / \mathrm{v})$ was used as the mobile phase at a flow rate of $0.3 \mathrm{~mL} / \mathrm{min}$, and the elution was monitored at $210 \mathrm{~nm}$. The concentration of iturin A was analyzed and quantified using an authentic reference standard (Sigma Chemicals, St. Louis, MO, USA). The content of iturin A was measured using triplicate samples.

\section{Determination of reducing sugar, free ammonium nitrogen concentrations and the viable cells}

The concentrations of reducing sugar in the fermentation were determined by the DNS method using 3, 5dinitrosalicylic acid reagent [25]. The concentration of free ammonium nitrogen (FAN) was determined using the ninhydrin colorimetric method [26]. The viable cell count during submerged fermentation was determined as follows: $0.5 \mathrm{~mL}$ of the sample was placed into a sterile $10 \mathrm{~mL}$ test tube, mixed thoroughly with $4.5 \mathrm{ml}$ of sterile distilled water and shaken at $150 \mathrm{rpm}$ on a vortex for 5 min at room temperature. The mixture was then serially diluted and spread onto LB agar plates. After $24 \mathrm{~h}$ of incubation at $28^{\circ} \mathrm{C}$, the number of colonies was counted and expressed as colony forming units (CFU).

\section{Determination of the iturin A stability to lipase}

First, submerged fermentation were performed in $250 \mathrm{~mL}$ flasks with $20 \mathrm{~mL}$ medium, containing (per liter): $60 \mathrm{~g}$ glucose, $1 \mathrm{~g} \mathrm{~K}_{2} \mathrm{HPO}_{4} \cdot 3 \mathrm{H}_{2} \mathrm{O}, 0.5 \mathrm{~g} \mathrm{MgSO}_{4} \cdot 7 \mathrm{H}_{2} \mathrm{O}, 0.005 \mathrm{~g}$ $\mathrm{MnSO}_{4} \cdot \mathrm{H}_{2} \mathrm{O}$, and $76.52 \mathrm{~g}$ RSM. After $72 \mathrm{~h}$ of fermentation, the fermentation broth was divided into two groups. Therein, one group supplemented with $5 \mathrm{U} / \mathrm{mL}$ lipase while the other without lipase addition. Then submerged fermentation was continued to be conducted at $28^{\circ} \mathrm{C}$ with a rotating speed of $220 \mathrm{rpm}$. And the concentrations of iturin $\mathrm{A}$ at different time $(0,24,48$ and $72 \mathrm{~h}$ ) were measured.

\section{Statistical analysis}

All experiments were performed in triplicate and the data were processed using Origin v8.6 software (Origin Lab Corp., Northampton, MA, USA).

\section{Results}

Influence of initial RSC and glucose concentrations on the production of iturin $\mathrm{A}$

In our previous study [4], the optimal initial RSM and glucose concentrations for iturin A production by $B$. subtilis 310 in submerged fermentation were found to be 90 and 20 $\mathrm{g} / \mathrm{L}$, respectively. Therefore, $20 \mathrm{~g} / \mathrm{L}$ initial glucose was used to test the influence of initial RSC concentration on iturin A production by $B$. amyloliquefaciens CX-20. As shown in Fig. 1a, the maximum iturin A final concentration $0.39 \mathrm{~g} / \mathrm{L}$ was obtained when the initial RSC concentration was $90 \mathrm{~g} /$ $\mathrm{L}$. With the increase of RSC concentration from 30 to $90 \mathrm{~g} /$ $\mathrm{L}$, the production of iturin A increased. However, the iturin A production started to decrease upon further increase of RSC concentration from 90 to $150 \mathrm{~g} / \mathrm{L}$. An interesting phenomenon was that the final reducing sugar concentrations increased almost linearly with the initial RSC concentrations. This might be positively related to the reducing sugar released from RSC during fermentation process. The initial reducing sugar concentration slightly decreased, which was speculated to be related to the Maillard reaction caused by the high-temperature sterilization due to the covalent bonds formed between a free reactive - $\mathrm{NH} 2$ group of an amino acid and the carbonyl group of a reducing sugar [27]. The concentration of final free ammonium nitrogen (FFAN) also increased linearly from 162.50 to $1266.95 \mathrm{mg} / \mathrm{L}$ with the RSC concentration increasing from 30 to $150 \mathrm{~g} / \mathrm{L}$. Compared with the FFAN concentration, the initial free ammonium nitrogen (IFAN) concentration increased slightly (Fig. 1b). This indicated that B. amyloliquefaciens CX-20 had a strong ability to hydrolyze the insoluble nitrogen source in RSC to produce soluble form, which was not 
a

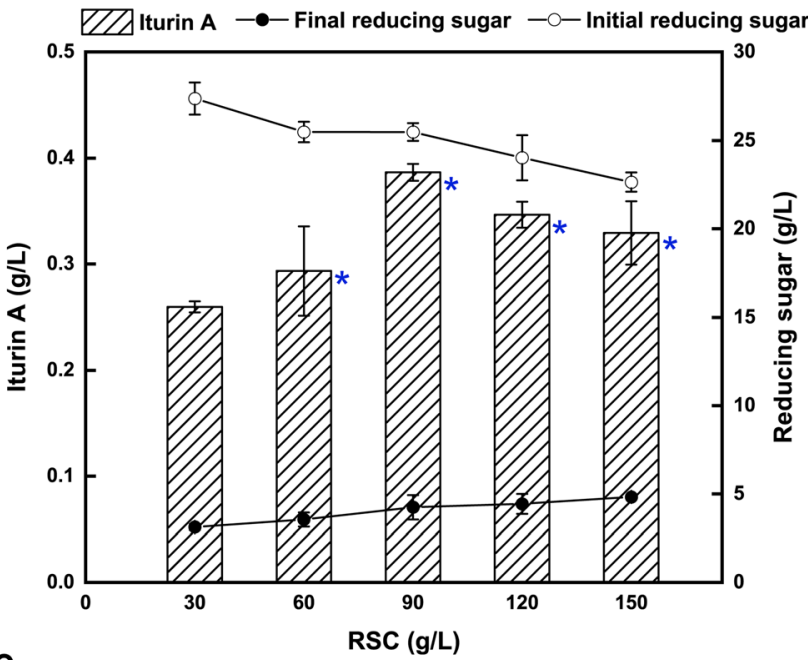

C

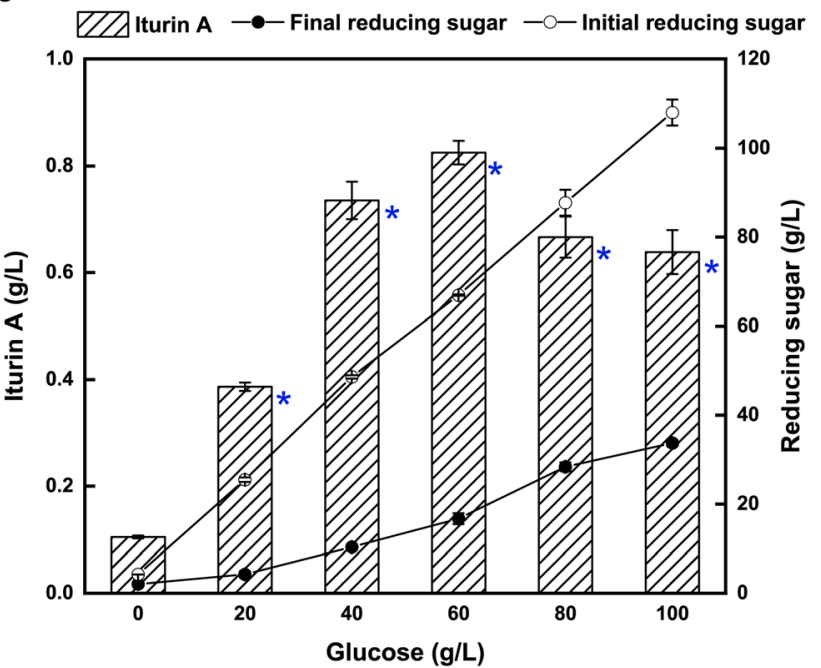

b

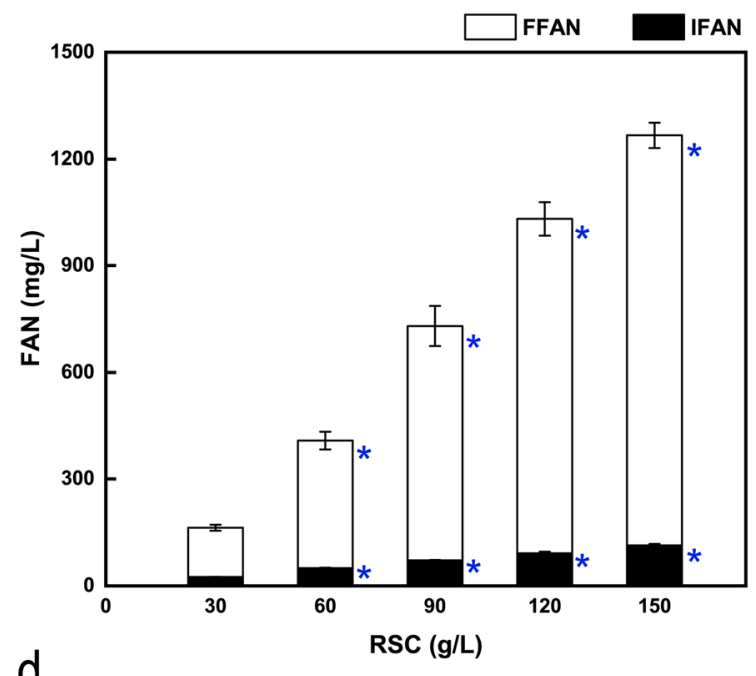

d

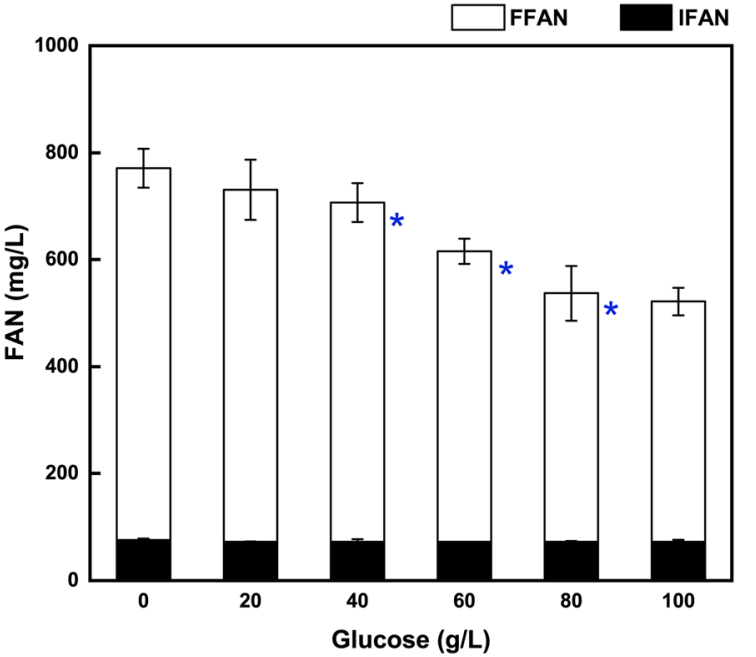

Fig. 1 Effects of different initial RSC and glucose concentrations on iturin A production, concentrations of reducing sugars and FAN at $72 \mathrm{~h}$ in shake flasks. a Effects of different initial RSC concentrations on iturin A production, initial and final concentrations of reducing sugars. $\mathbf{b}$ Effects of different initial RSC concentrations on the concentrations of IFAN and FFAN. c Effects of different initial glucose concentrations on iturin A production, initial and final concentrations of reducing sugars. $\mathbf{d}$ Effects of different initial glucose concentrations on the concentrations of IFAN and FFAN. $P<0.05$ was indicated by blue asterisk. In order to avoid the effects of fermentation volume among different flasks, the sample size was same of $1 \mathrm{~mL}$ from each flask for the analysis at the beginning and end of fermentation $(0$ and $72 \mathrm{~h}$ )

surprisingly considering the strong intrinsic protease activity of many Bacillus [4]. Genome and transcriptome analysis of B. amyloliquefaciens CX-20 demonstrated that it could not only produce proteases that hydrolyze proteins into peptides and amino acids, but also phytase, xylanase, cellulase and lipase enzyme, which was similar to Aspergillus oryzae and could result in the release of phosphate and the production of simple sugars to be used as carbon source for the growth of the microorganisms [28]. Therefore, Bacillus has intrinsic advantages for direct bio-utilization of RSC for the production of microbial metabolites $[4,5]$.

According to above results, the initial RSC concentration of $90 \mathrm{~g} / \mathrm{L}$ was fixed to determine the optimum concentration of glucose and further improve the production of iturin A. Subsequently, the effects of different glucose concentrations ranging from 0 to $100 \mathrm{~g} / \mathrm{L}$ on iturin A production were explored. It was clearly demonstrated that the optimal initial glucose concentration for iturin A production was $60 \mathrm{~g} / \mathrm{L}$, and the corresponding maximum iturin $\mathrm{A}$ concentration reached $0.82 \mathrm{~g} / \mathrm{L}$. Nevertheless, $0.10 \mathrm{~g} / \mathrm{L}$ of iturin A was still produced even without adding glucose (Fig. 1c). As a complex mixture, RSM can not only be used as a nitrogen source $[4,5,15,17,29]$, but can also provide carbon $[14,16]$ for the growth and metabolism of microorganisms. According to our results, RSC could also be used as both a carbon source and a nitrogen source. As a 
carbon source, RSC seemed to be efficient, since the final concentration of reducing sugars was $2.05 \mathrm{~g} / \mathrm{L}$ from initial $4.22 \mathrm{~g} / \mathrm{L}$ after $72 \mathrm{~h}$ fermentation. This further proved that B. amyloliquefaciens CX-20 could produce many enzymes to hydrolyze the carbohydrates of RSC into reducing sugars. It has been reported that rapeseed oil could be used as a source of carbon to ferment microbial products such as lipase [23], erythromycin [30] and isocitric acid [31]. However, whether the residual oil in RSC could be used as a carbon source for iturin A production by B. amyloliquefaciens CX-20 was still unclear. But RSC was insufficient to support the fermentation and synthesis of iturin A by B. amyloliquefaciens CX-20 as the sole carbon source. Accordingly, with the increase of initial glucose concentration from 0 to $60 \mathrm{~g} / \mathrm{L}$, the production of iturin A continued rising, but decreased when the initial glucose concentration was raised above $60 \mathrm{~g} / \mathrm{L}$. Although the final concentration of reducing sugars increased with the increase of initial glucose concentration, the change trend of the FFAN concentration (decreased from 771 to $522 \mathrm{mg} / \mathrm{L}$ ) was opposite (Fig. 1d). This indicated that higher glucose or RSC concentrations could mutually promote the corresponding substrate consumption, but might not be necessary for improving iturin A production.

\section{Influence of lipase loading on the production of iturin A from RSC}

Different concentrations of lipase (ranging from 0 to 10 $\mathrm{U} / \mathrm{mL}$ ) were added into the medium containing the optimal concentrations of $90 \mathrm{~g} / \mathrm{L}$ RSC and $60 \mathrm{~g} / \mathrm{L}$ glucose at the beginning of the process to enable simultaneous hydrolysis and fermentation. As shown in Fig. 2, with the increase of lipase concentration from 0 to $0.5 \mathrm{U} / \mathrm{mL}$, the production of iturin A gradually increased. However, with the further increase of lipase concentration (from $0.5-10 \mathrm{U} / \mathrm{mL}$ ), the production of iturin A began to decrease. When the concentration of lipase was $0.5 \mathrm{U} / \mathrm{mL}$, the iturin A production reached a maximum of $1.14 \mathrm{~g} / \mathrm{L}$, which represented a $38.15 \%$ increase over the fermentation without any lipase addition. By contrast, when the concentration of lipase reached $10 \mathrm{U} / \mathrm{mL}$, the final concentration of iturin A decreased to $0.59 \mathrm{~g} / \mathrm{L}$, which was even $27.94 \%$ lower than that without any lipase addition. The change trend of the final reducing sugar concentration was similar to that of iturin A production. Lipases are a group of enzymes that hydrolyze the ester bonds in triacylglycerides to form fatty acids and glycerol, or catalyze the synthesis of esters under certain conditions [32]. The lipase used in this study was a mixture used as a feed additive to aid animal digestion. Therefore, we speculated that the appropriate addition of lipase might help hydrolyze the residual oil in RSC into fatty acids and glycerol. Notably, glycerol has been proved to be a more suitable carbon source for iturin A production than glucose (data not shown). This helps explain why the FFAN concentrations with added lipase was lower than that without lipase, since the released glycerol could also promote the consumption of the nitrogen source (Fig. 2b). However, excess lipase had a negative effect on the production of iturin A.
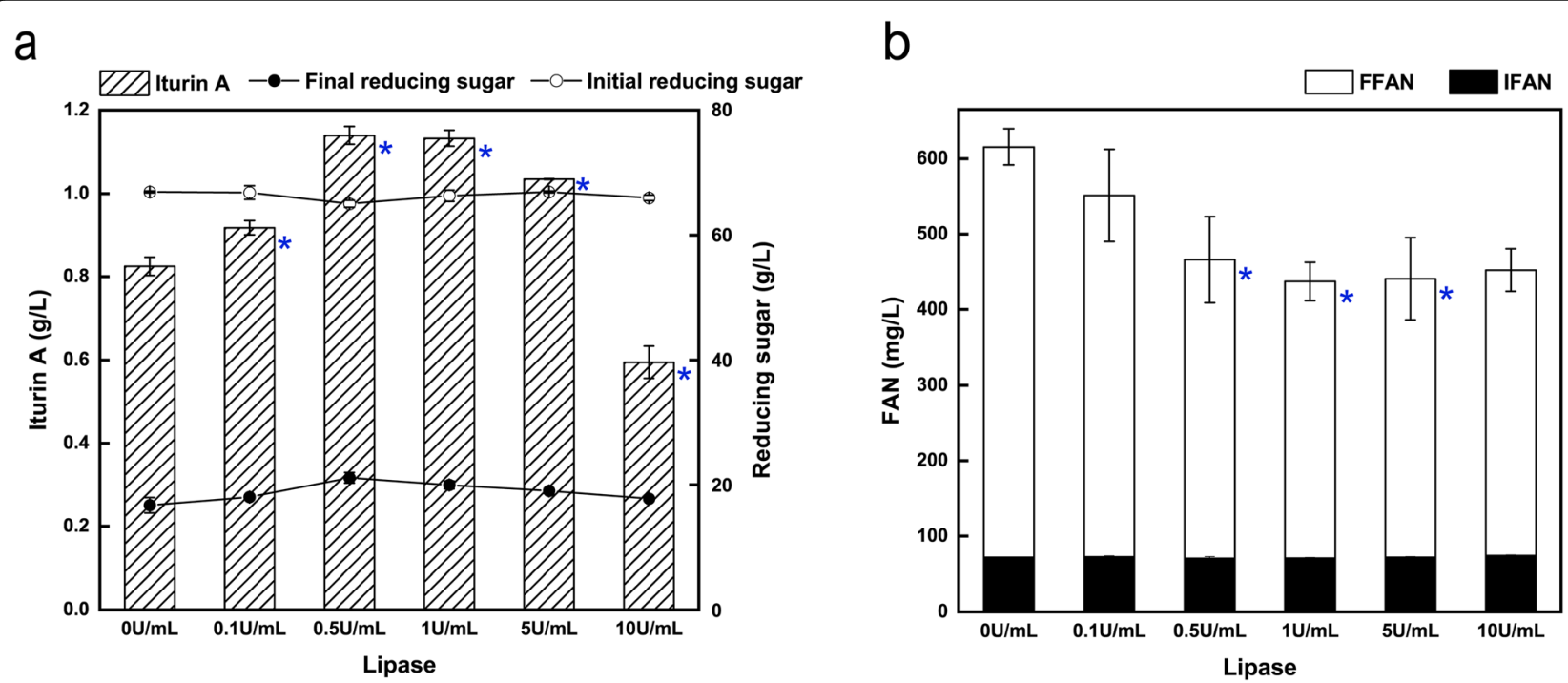

Fig. 2 Effects of lipase loading on iturin A production, concentrations of reducing sugars and FAN at $72 \mathrm{~h}$ in shake flasks. a Effects of lipase loading on iturin A production, initial and final concentrations of reducing sugars. $\mathbf{b}$ Effects of lipase loading on the concentrations of IFAN and FFAN. $P<0.05$ was indicated by blue asterisk. In order to avoid the effects of fermentation volume among different flasks, the sample size was same of $1 \mathrm{~mL}$ from each flask for the analysis at the beginning and end of fermentation ( 0 and $72 \mathrm{~h}$ ) 


\section{Influence of lipids and lipase on the fermentation of} iturin A

As shown in Table 1, the content of protein in RSC was $33.5 \%$ while the protein content in RSM was $39.4 \%$. Therefore, the protein content in $90 \mathrm{~g} / \mathrm{L}$ RSC was equal to that of $76.52 \mathrm{~g} / \mathrm{L} \mathrm{RSM}$, and the latter was added to substitute $90 \mathrm{~g} / \mathrm{L}$ RSC to simulate the protein content in the original medium. Because the crude fat content of RSM was $1.6 \%$ while that of RSC was $14.4 \%$, the crude fat content of the medium containing $90 \mathrm{~g} / \mathrm{L} \mathrm{RSC}$ was $12.96 \mathrm{~g} / \mathrm{L}$, while that of the medium containing $76.52 \mathrm{~g} / \mathrm{L}$ RSM was $1.22 \mathrm{~g} / \mathrm{L}$. The difference of crude fat between the two media was $11.74 \mathrm{~g} / \mathrm{L}$. In order to explore the effect of crude fat on iturin A production, 0, 6, 12 or $24 \mathrm{~g} /$
$\mathrm{L}$ of natural rapeseed oil was added into the medium containing $76.52 \mathrm{~g} / \mathrm{L}$ RSM (Fig. 3a). After $72 \mathrm{~h}$ of fermentation, the final concentration of iturin A without added oil was $0.95 \mathrm{~g} / \mathrm{L}$, which was $15.56 \%$ higher than that of the $90 \mathrm{~g} / \mathrm{L}$ RSC medium. With the increase of oil concentration, the trend of iturin A production was gradually decreasing. When $12 \mathrm{~g} / \mathrm{L}$ rapeseed oil was added into the medium, the iturin A production decreased to $0.79 \mathrm{~g} / \mathrm{L}$. Although the production of iturin A decreased 17.46\% compared to that produced without any oil addition, its value was very close to that produced with $90 \mathrm{~g} / \mathrm{L} \mathrm{RSC}$ $(0.82 \mathrm{~g} / \mathrm{L})$. When $6 \mathrm{~g} / \mathrm{L}$ rapeseed oil was added to the medium, the iturin A production decreased to $0.93 \mathrm{~g} / \mathrm{L}$, which was very close to the value obtained without adding
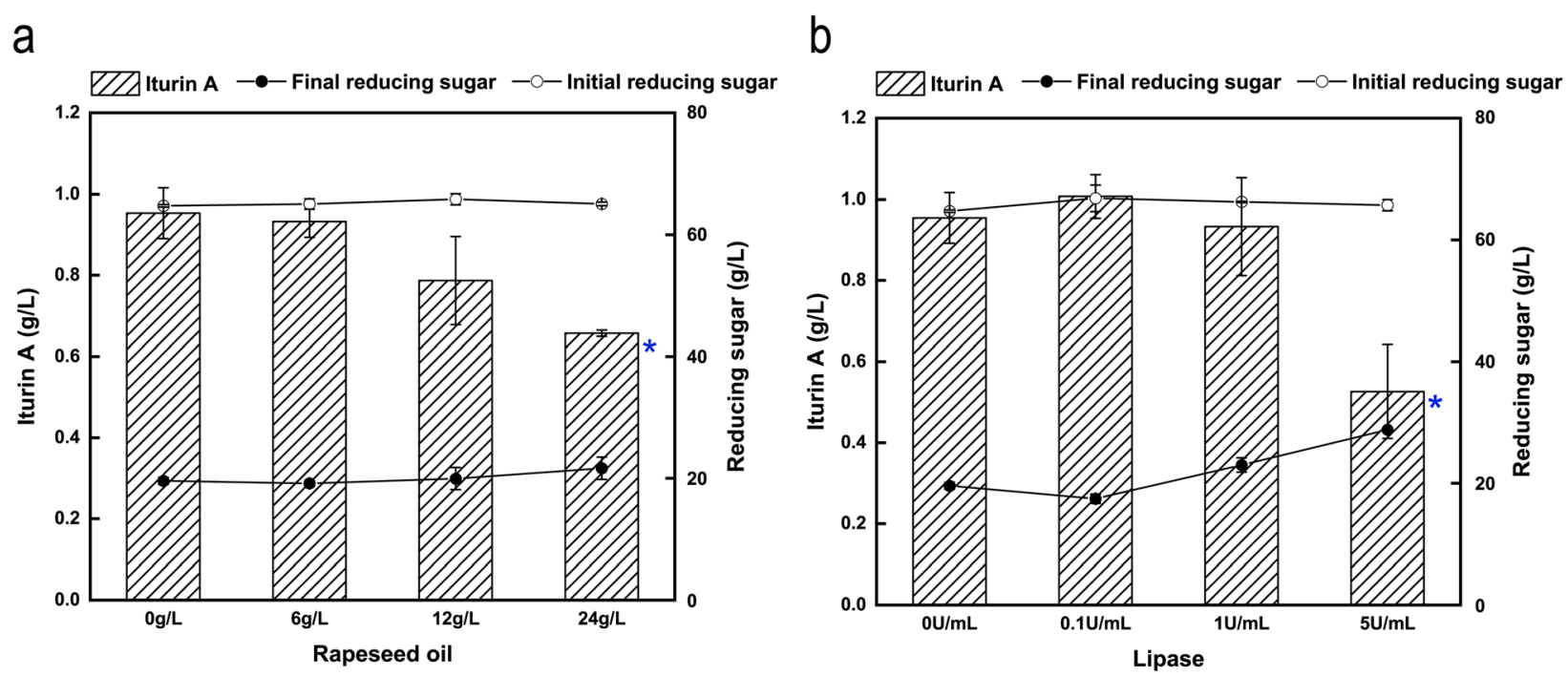

C

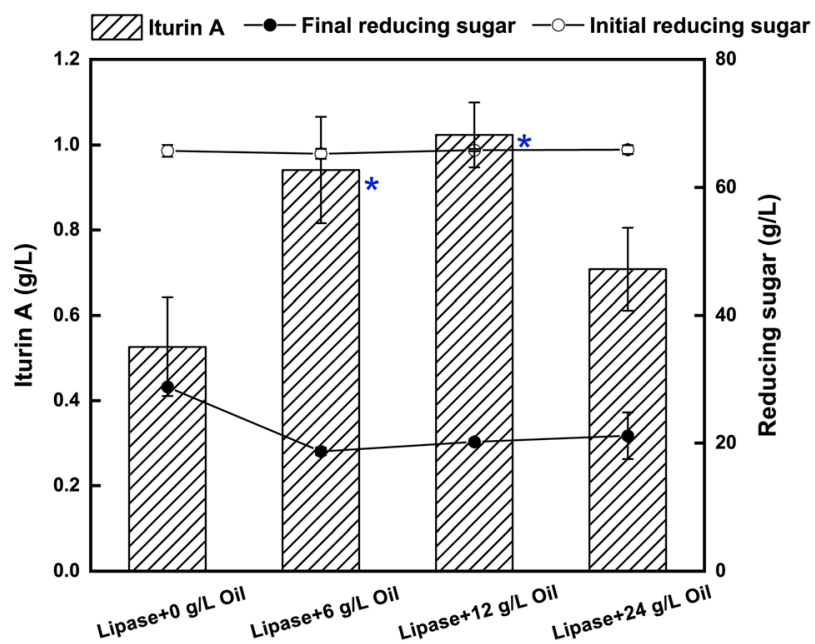

Fig. 3 Effects of different rapeseed oil and lipase concentrations. a Effects of different rapeseed oil concentrations on iturin A production, initial and final concentrations of reducing sugars. $\mathbf{b}$ Effects of different initial lipase concentrations on iturin A production, initial and final concentrations of reducing sugars. c Effects of different ratio of lipase and rapeseed oil on iturin A production, initial and final concentrations of reducing sugars. $P<0.05$ was indicated by blue asterisk. In order to avoid the effects of fermentation volume among different flasks, the sample size was same of $1 \mathrm{~mL}$ from each flask for the analysis at the beginning and end of fermentation ( 0 and $72 \mathrm{~h}$ ) 
oil. Because the lipopeptide products possess surfactin activity and cause foam formation, it is difficult to control the fermentation, which also restricts the industrialization of lipopeptide production [2]. Rapeseed oil has been found to be an efficient antifoam compound [33]. Our results also demonstrated that when the concentration of added rapeseed oil was lower than $0.6 \%$, there was almost no negative effect on iturin A production. Therefore, rapeseed oil seemed to also be a suitable antifoam compound for iturin A production. However, when $24 \mathrm{~g} / \mathrm{L}$ rapeseed oil was added into the medium, the iturin A production decreased to $0.66 \mathrm{~g} / \mathrm{L}$.

From the results shown in Fig. 2, we found that an appropriate concentration of lipase could improve the production of iturin A. Conversely, its production would be reduced when the concentration of lipase was too high. The oil content of RSM was lower than that of RSC (Table 1). Therefore, in theory, the optimal concentration of lipase for RSM should decrease accordingly. As expected, when the concentration of lipase was 0.1 $\mathrm{U} / \mathrm{mL}$, the iturin A production had a slight increase, from $0.95 \mathrm{~g} / \mathrm{L}$ to $1.01 \mathrm{~g} / \mathrm{L}$, but when the lipase concentration was increased to $1 \mathrm{U} / \mathrm{mL}$, the final concentration of iturin A was slight lower than that without any lipase added $(0.95 \mathrm{~g} / \mathrm{L}$ vs. $0.93 \mathrm{~g} / \mathrm{L})$. When the lipase concentration was increased to $5 \mathrm{U} / \mathrm{mL}$, the final concentration of iturin A drastically decreased to $0.53 \mathrm{~g} / \mathrm{L}$, which was only $55.14 \%$ of that produced without any added lipase (Fig. 3b). At the same time, the final reducing sugar concentration gradually increased with the increase of lipase concentration when the lipase concentration was more than $0.1 \mathrm{U} / \mathrm{mL}$.

Although the production of iturin A decreased slightly when RSC was used as nitrogen source if the lipase concentration was increased to $5 \mathrm{U} / \mathrm{mL}$, the production of iturin A apparently decreased when RSM containing an equal protein content was used as the nitrogen source. Therefore, proper proportions of rapeseed oil and lipase appeared to be crucial for optimal iturin A production. As shown in Fig. 3b, a lipase concentration of $5 \mathrm{U} / \mathrm{mL}$ had a significant influence on the production of iturin A from RSM, and was chosen to explore the appropriate ratio of rapeseed oil to lipase. As shown in Fig. 3c, with the increase of rapeseed oil concentration from 0 to 12 $\mathrm{g} / \mathrm{L}$, iturin A production continued rising and reached a maximum of $1.02 \mathrm{~g} / \mathrm{L}$, which was almost equal to the iturin A production $(1.03 \mathrm{~g} / \mathrm{L})$ produced from $90 \mathrm{~g} / \mathrm{L}$ RSC with $5 \mathrm{U} / \mathrm{mL}$ lipase, when the addition of rapeseed oil was $12 \mathrm{~g} / \mathrm{L}$. However, when the concentration of rapeseed oil was increased to $24 \mathrm{~g} / \mathrm{L}$, the final concentration of iturin A decreased to $0.61 \mathrm{~g} / \mathrm{L}$, which was only $59.42 \%$ of that obtained with $12 \mathrm{~g} / \mathrm{L}$ rapeseed oil.

There are many possible explanations why lipase and rapeseed oil could reduce each other's negative effects on iturin A production. The most likely one is related to microbial growth. Therefore, we examined the growth curves of Bacillus under several representative conditions. As shown in Fig. 4, when $12 \mathrm{~g} / \mathrm{L}$ rapeseed oil or $5 \mathrm{U} / \mathrm{mL}$ lipase was added separately into the medium containing $76.52 \mathrm{~g} /$ L RSM, both the specific growth rates $\left(0.56\right.$ and $0.52 \mathrm{~h}^{-1}$ from $1.03 \mathrm{~h}^{-1}$ ) and the ultimate maximum viable cell count (about $8 \times 10^{8}$ and $3 \times 10^{8} \mathrm{~mL}^{-1}$ from about $8 \times 10^{9}$ $\mathrm{mL}^{-1}$ ) were significantly reduced compared with the medium without either rapeseed oil or lipase. However, when $12 \mathrm{~g} / \mathrm{L}$ rapeseed oil and $5 \mathrm{U} / \mathrm{mL}$ lipase were added at the same time, both the specific growth rate $\left(0.80 \mathrm{~h}^{-1}\right)$ and the ultimate maximum viable cell count (about $2 \times$ $10^{9} \mathrm{~mL}^{-1}$ ) showed an obvious recovery.

\section{Discussion}

The feasibility of using RSM as nitrogen sources in microbial fermentation processes has been reported [4, 5, 14-18]. However, as the low-cost by-product of the processing of oil crops, RSC also contains a high content of oil in addition to its protein content. Whether the residual oil in RSC might affect the production of microbial metabolites including iturin A, and whether lipase could be useful for improving their productions, were still not clear.

In this study, the feasibility of using untreated RSC as nitrogen source to produce the valuable cyclic lipopeptide antibiotic iturin A using B. amyloliquefaciens CX-20 in submerged fermentation was first investigated. The maximum production of iturin A was $0.82 \mathrm{~g} / \mathrm{L}$ at the optimal initial RSC and glucose concentrations of 90 and $60 \mathrm{~g} / \mathrm{L}$, respectively. However, when RSC was substituted with

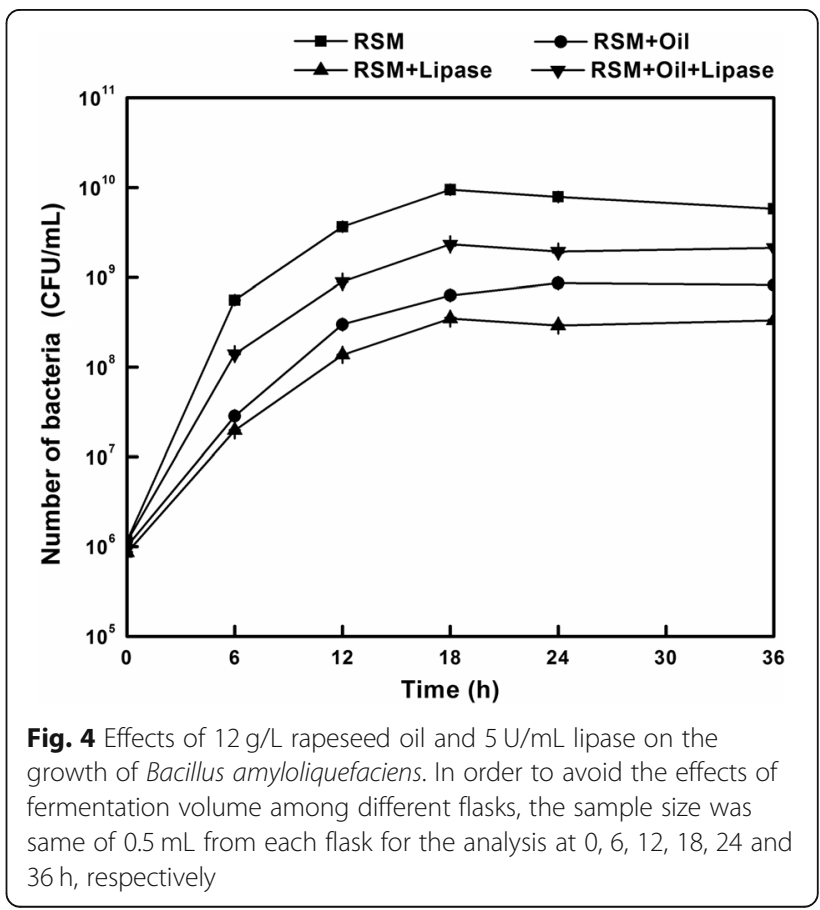


RSM as nitrogen source based on equal protein content, the final concentration of iturin A was improved to $0.95 \mathrm{~g} /$ L. Excess rapeseed oil over $6 \mathrm{~g} / \mathrm{L}$ would suppress the production of iturin A in B. amyloliquefaciens CX-20. Kamzolova et al. [31] used rapeseed oil as a source of carbon and energy to produce isocitric acid in the unconventional yeast Yarrowia lipolytica. The first step of utilization of rapeseed oil by the yeast was its hydrolysis by extracellular lipases that produce glycerol and fatty acids. Moreover, the fatty acid profile of rapeseed oil (\%, by mass) was found to be C16:0, 4.0; C18:0, 1.2; C18:1, 58.8; C18:2, 28.1; C18:3, 5.9 with a total unsaturated fatty acid mass fraction of $93.6 \%$ [34]. Therein, palmitic acid was proved to be a useful precursor whose addition could enhance the production of iturin A [19]. Oils are the essential components of industrial fermentation media and have been routinely added to media for the production of secondary metabolites. They have been used as antifoams, sole carbon sources, auxiliary carbon sources, to provide precursors for antibiotic synthesis and to remove the antibiotic from bacterial access and reduce its suppressive effect on antibiotic production [30]. However, it was considered possible that oil might form a thin film on the surface of the medium, decreasing the oxygen dissolution efficiency, which may influence the production of iturin A [35]. Wu et al. [19] verified the negative effects on iturin A production after the addition of either palm or soybean oil. Our results confirmed that rapeseed oil also had a negative effect on iturin A production, which might be a key factor influencing the utilization of RSC.

The nutrients in rapeseed oil by-products cannot be directly assimilated by the majority of industrial microorganisms without pretreatment due to its particular physical and chemical structure [27, 36]. Although many studies investigated ways of using enzymes such as proteases, cellulase and viscozyme to enhance the value of nitrogen from the rapeseed by-products for microbial fermentations [16, 29], we are not aware of any studies on utilizing lipase to improve the substrates' value for microbial production. To our best knowledge, this might be the first study on directly using lipase for the production of iturin A from rapeseed oil by-products. At the optimal lipase concentration of $0.5 \mathrm{U} / \mathrm{mL}$, the maximal production of iturin A from RSC reached $1.14 \mathrm{~g} / \mathrm{L}$, which was $38.15 \%$ higher than that without any lipase supplement. The experiments of RSC substitution with RSM based on equal protein content further proved that excess concentration of rapeseed oil or lipase would have a negative effect on iturin A production. However, the proper ratio of these two elements for simultaneous fermentation by B. amyloliquefaciens CX-20 would mitigate the effects of each, and could even boost the amount of iturin A produced from RSC. These variation trends seemed similar to that of microbial growth.
Therefore, we concluded that the negative effect caused by rapeseed oil or lipase might be related to their corresponding effects on cell growth, although this was likely not the only reason. After all, when both were added at the same time, although the growth rate and the ultimate maximum viable count were still lower than that of the control, the production of iturin A was slightly higher. This was consistent with the study by Jin et al. [4] whose research demonstrated that ammonium nitrate was a good nitrogen source for Bacillus growth while it was not suitable for iturin A production. More work would be needed to further elucidate this phenomenon.

Iturin A consisted of a cyclic heptapeptide linked to a 14-17 carbons $\beta$-hydroxy fatty-acid chain. Therefore, it was speculated that lipase might cleave the fatty acid chain of iturin A so that reduced iturin A production. However, as shown in Fig. 5, when the deviations were taken into consideration, the addition of excess lipase (5 $\mathrm{U} / \mathrm{mL}$ ) after $72 \mathrm{~h}$ fermentation had almost no effect on the stability of iturin A from RSM, compared with that without any lipase supplement. Although lipopeptides have been reported to have excellent thermal and chemical stability [2], this might be the first study to investigate the good resistance of iturin A to lipase.

\section{Conclusion}

Compared with RSM, RSC has been rarely used as a raw material for microbial fermentation due to its high content of residual oil. This study not only demonstrated that the residual oil in RSC had a negative effect on iturin A production, but also provided an efficient

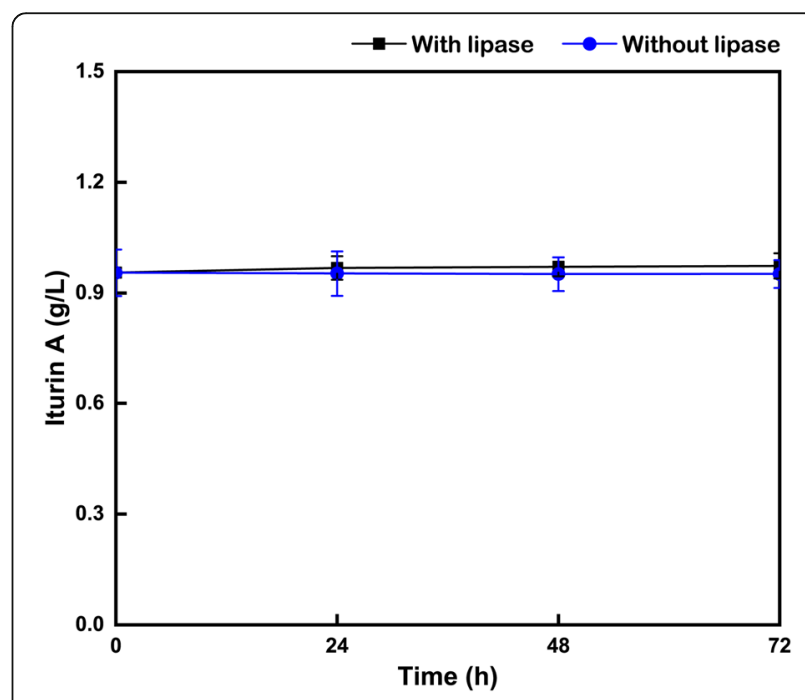

Fig. 5 Effects of excess lipase on the stability of iturin A. In order to avoid the effects of fermentation volume among different flasks, the sample size was same of $0.5 \mathrm{~mL}$ from each flask for the analysis at 0 , 24,48 and 72 h, respectively 
means to solve this problem by adding a commerciallyavailable feed-processing lipase for simultaneous hydrolysis and fermentation. When the optimal lipase concentration of $0.5 \mathrm{U} / \mathrm{mL}$ was added into the RSC medium, the final concentration of iturin $\mathrm{A}$ increased from 0.82 to $1.14 \mathrm{~g} / \mathrm{L}$, which was also higher than the $0.95 \mathrm{~g} / \mathrm{L}$ produced in RSM medium containing an equal protein content. By using RSM and rapeseed oil to simulate RSC, excess rapeseed oil was proved to suppress the production of iturin $\mathrm{A}$, which might be related to the oil forming a thin film on the surface of the medium, and thus decreasing the oxygen dissolution efficiency and cell growth. The proper supplementation ratio of the lipase for simultaneous hydrolysis and fermentation by $B$. amyloliquefaciens CX-20 was verified to mitigate the effect of rapeseed oil for the first time in this study. This research is important not only for improving the economic value of RSC and decreasing the production cost of iturin $\mathrm{A}$, but also for establishing a new way to increase the value of rapeseed oil for microbial fermentation, either as antifoams, auxiliary carbon sources, or providing precursors for antibiotic synthesis.

\section{Abbreviations}

CFU: Colony forming units; FAN: Free ammonium nitrogen; FFAN: Final free ammonium nitrogen; IFAN: Initial free ammonium nitrogen; LB: Luria-Bertani; RSC: Rapeseed cake; RSM: Rapeseed meal

\section{Acknowledgements}

Not applicable

\section{Authors' contributions}

CWC, WX and HFH conceived and designed the experiments. CWC, LX, MXL, KYP, YMM performed experiments. CWC and LX analyzed the data and prepared the Figures and Tables and wrote the manuscript. WX, HFH and CSW corrected and proofread the manuscript. All authors read and approved the final manuscript.

\section{Funding}

The strain and enzyme acquisition, preliminary experiments and data analysis were funded by the Natural Science Foundation of Hubei Province (Grant Number 2019CFB378) and Ministry of Science and Technology of the People's Republic of China (Grant Number 2016YFD0501209). The experiment performance, data collection, analysis and interpretation of data were supported by the Chinese Academy of Agricultural Sciences (Grant Number CAAS-ASTIP-2016-OCRI).

\section{Availability of data and materials}

All data generated or analysed during this study are included in this published article.

\section{Ethics approval and consent to participate}

This article does not contain any studies with human participants or animals performed by any of the authors.

\section{Consent for publication}

Not applicable.

\section{Competing interests}

The authors declare that they have no competing interests.

\section{Author details}

'Oil Crops Research Institute of the Chinese Academy of Agricultural Sciences, Wuhan 430062, People's Republic of China. ${ }^{2}$ Key Laboratory of
Biology and Genetic Improvement of Oil Crops, Ministry of Agriculture, Wuhan 430062, People's Republic of China. ${ }^{3}$ Hubei Collaborative Innovation Center for Green Transformation of Bio-Resources, Environmental Microbial Technology Center of Hubei Province, College of Life Sciences, Hubei University, Wuhan 430062, People's Republic of China. ${ }^{4}$ Oil Crops and Lipids Process Technology National \& Local Joint Engineering Laboratory, Wuhan 430062, People's Republic of China. ${ }^{5}$ Hubei Key Laboratory of Lipid Chemistry and Nutrition, Wuhan 430062, People's Republic of China.

Received: 19 February 2019 Accepted: 5 December 2019

Published online: 16 December 2019

\section{References}

1. Khan N, Maymon M, Hirsch AM. Combating Fusarium infection using Bacillus-based antimicrobials. Microorganisms. 2017;5(4):E75.

2. Zhao H, Shao D, Jiang C, Shi J, Li Q, Huang Q, Rajoka MSR, Yang H, Jin M. Biological activity of lipopeptides from Bacillus. Appl Microbiol Biotechnol. 2017;101(15):5951-60.

3. Kawagoe Y, Shiraishi S, Kondo H, Yamamoto S, Aoki Y, Suzuki S. Cyclic lipopeptide iturin A structure-dependently induces defense response in Arabidopsis plants by activating SA and JA signaling pathways. Biochem Biophys Res Commun. 2015;460(4):1015-20.

4. Jin H, Zhang X, Li K, Niu Y, Guo M, Hu C, Wan X, Gong Y, Huang F. Direct bio-utilization of untreated rapeseed meal for effective iturin A production by Bacillus subtilis in submerged fermentation. PLoS One. 2014;9(10): e111171.

5. Jin H, Li K, Niu Y, Guo M, Hu C, Chen S, Huang F. Continuous enhancement of iturin A production by Bacillus subtilis with a stepwise two-stage glucose feeding strategy. BMC Biotechnol. 2015;15:53.

6. Mizumoto S, Hirai M, Shoda M. Enhanced iturin A production by Bacillus subtilis and its effect on suppression of the plant pathogen Rhizoctonia solani. Appl Microbiol Biotechnol. 2007;75(6):1267-74.

7. Zohora US, Rahman MS, Khan AW, Okanami M, Ano T. Improvement of production of lipopeptide antibiotic iturin A using fish protein. J Environ Sci (China). 2013;25(Suppl 1):S2-7.

8. Yao D, Ji Z, Wang C, Qi G, Zhang L, Ma X, Chen S. Co-producing iturin A and poly-y-glutamic acid from rapeseed meal under solid state fermentation by the newly isolated Bacillus subtilis strain 3-10. World $J$ Microbiol Biotechnol. 2012;28(3):985-91.

9. Shi C, He J, Yu J, Yu B, Huang Z, Mao X, Zheng P, Chen D. Solid state fermentation of rapeseed cake with Aspergillus niger for degrading glucosinolates and upgrading nutritional value. J Anim Sci Biotechnol. 2015;6(1):13.

10. Drazbo A, Ognik K, Zaworska A, Ferenc K, Jankowski J. The effect of raw and fermented rapeseed cake on the metabolic parameters, immune status, and intestinal morphology of turkeys. Poult Sci. 2018;97(11):3910-20.

11. Fang ZF, Peng J, Tang TJ, Liu ZL, Dai JJ, Jin LZ. Xylanase supplementation improved digestibility and performance of growing pigs fed Chinese double-low rapeseed meal inclusion diets: in vitro and in vivo studies. AsianAustralas J Anim Sci. 2007:11:1721-8.

12. Smulikowska S, Czerwiński J, Mieczkowska A. Effect of an organic acid blend and phytase added to a rapeseed cake-containing diet on performance, intestinal morphology, caecal microflora activity and thyroid status of broiler chickens. J Anim Physiol Anim Nutr (Berl). 2010;94(1):15-23.

13. Kaewtapee C, Mosenthin R, Nenning S, Wiltafsky M, Schäffler M, Eklund M, Rosenfelder-Kuon P. Standardized ileal digestibility of amino acids in European soya bean and rapeseed products fed to growing pigs. J Anim Physiol Anim Nutr (Berl). 2018;102(2):e695-705.

14. Almeida JM, Lima VA, Giloni-Lima PC, Knob A. Canola meal as a novel substrate for $\beta$-glucosidase production by Trichoderma viride: application of the crude extract to biomass saccharification. Bioprocess Biosyst Eng. 2015; 38(10):1889-902.

15. Chatzifragkou A, Papanikolaou S, Kopsahelis N, Kachrimanidou V, Dorado MP, Koutina AA. Biorefinery development through utilization of biodiesel industry by-products as sole fermentation feedstock for 1, 3-propanediol production. Bioresour Technol. 2014;159:167-75.

16. Chen KQ, Zhang H, Miao YL, Wei P, Chen JY. Simultaneous saccharification and fermentation of acid-pretreated rapeseed meal for succinic acid production using Actinobacillus succinogenes. Enzym Microb Technol. 2011; 48:339-44. 
17. García IL, López JA, Dorado MP, Kopsahelis N, Alexandri M, Papanikolaou S, Villar MA, Koutinas AA. Evaluation of by-products from the biodiesel industry as fermentation feedstock for poly (3-hydroxybutyrateco-3hydroxyvalerate) production by Cupriavidus necator. Bioresour Technol. 2013;130:16-22.

18. Uckun Kiran E, Trzcinski A, Webb C. Microbial oil produced from biodiesel by-products could enhance overall production. Bioresour Technol. 2013;129:650-4.

19. Wu JY, Liao JH, Shieh CJ, Hsieh FC, Liu YC. Kinetic analysis on precursors for iturin A production from Bacillus amyloliquefaciens BPD1. J Biosci Bioeng. 2018;126(5):630-5.

20. Gupta R, Gupta N, Rathi P. Bacterial lipases: an overview of production, purification and biochemical properties. Appl Microbiol Biotechnol. 2004; 64(6):763-81.

21. Hasan F, Shah AA, Hameed A. Industrial applications of microbial lipases. Enzym Microb Technol. 2006;39:235-51.

22. Salihu A, Alam MZ, AbdulKarim MI, Salleh HM. Lipase production: an insight in the utilization of renewable agricultural residues. Resour Conserv Recycl. 2012;58:36-44.

23. Boratyński F, Szczepańska E, Grudniewska A, Gniłka R, Olejniczak T. Improving of hydrolases biosythesis by solid-state fermentation of Penicillium camemberti on rapeseed cake. Sci Rep. 2018;8(1):10157.

24. Chen W, Ma X, Wang X, Chen S, Rogiewicz A, Slominski B, Wan X, Huang F. Establishment of a rapeseed meal fermentation model for iturin $\mathrm{A}$ production by Bacillus amyloliquefaciens CX-20. Microb Biotechnol. 2019; 12(6):1417-29.

25. Miller GL. Use of dinitrosalicylic acid reagent for determination of reducing sugar. Anal Chem. 1959;31:426-8.

26. Lie S. The EBC-ninhydrin method for determination of free alpha amino nitrogen. J Inst Brew. 1973;79:37-41

27. Salazar-Villanea S, Butré Cl, Wierenga PA, Bruininx EMAM, Gruppen $\mathrm{H}$, Hendriks WH, van der Poel AFB. Apparent ileal digestibility of Maillard reaction products in growing pigs. PLoS One. 2018;13(7):e0199499.

28. Wang RH, Shaarani SM, Godoy LC, Melikoglu M, Vergara CS, Koutinas A, Webb C. Bioconversion of rapeseed meal for the production of a generic feedstock. Enzym Microb Technol. 2010;47:77-83.

29. Uckun Kiran E, Salakkam A, Trzcinski AP, Bakir U, Webb C. Enhancing the value of nitrogen from rapeseed meal for microbial oil production. Enzym Microb Technol. 2012;50:337-42.

30. Hamedi J, Malekzadeh F, Saghafi-nia AE. Enhancing of erythromycin production by Saccharopolyspora erythraea with common anduncommon oils. J Ind Microbiol Biotechnol. 2004;31(10):447-56.

31. Kamzolova SV, Dedyukhina EG, Samoilenko VA, Lunina JN, Puntus IF, Allayarov RL, Chiglintseva MN, Mironov AA, Morgunov IG. Isocitric acid production from rapeseed oil by Yarrowia lipolytica yeast. Appl Microbiol Biotechnol. 2013;97(20):9133-44.

32. Ma RJ, Wang YH, Liu L, Bai LL, Ban R. Production enhancement of the extracellular lipase LipA in Bacillus subtilis: effects of expression system and sec pathway components. Protein Expr Purif. 2018;142:81-7.

33. Kougias PG, Tsapekos P, Boe K, Angelidaki I. Antifoaming effect of chemical compounds in manure biogas reactors. Water Res. 2013;47(16):6280-8.

34. Kamzolova SV, Allayarov RK, Lunina JN, Morgunov IG. The effect of oxalic and itaconic acids on threo-ds-isocitric acid production from rapeseed oil by Yarrowia lipolytica. Bioresour Technol. 2016;206:128-33.

35. Shih IL, Lin CY, Wu JY, Hsieh C. Production of antifungal lipopeptide from Bacillus subtilis in submerged fermentation using shake flask and fermentor. Korean J Chem Eng. 2009;26:1652-61.

36. Ramachandran S, Singh SK, Larroche C, Soccol CR, Pandey A. Oil cakes and their biotechnological applications--a review. Bioresour Technol. 2007:98:2000-9.

\section{Publisher's Note}

Springer Nature remains neutral with regard to jurisdictional claims in published maps and institutional affiliations.

Ready to submit your research? Choose BMC and benefit from:

- fast, convenient online submission

- thorough peer review by experienced researchers in your field

- rapid publication on acceptance

- support for research data, including large and complex data types

- gold Open Access which fosters wider collaboration and increased citations

- maximum visibility for your research: over $100 \mathrm{M}$ website views per year

At BMC, research is always in progress.

Learn more biomedcentral.com/submissions 